\title{
Research on Thermal Power Plant Location Based on Rough Set and Interval-valued Fuzzy Number
}

\author{
Wei SUN \& Ming QIN \\ Dept of Business Administration, North China Electric Power University, Baoding, Hebei, China
}

\begin{abstract}
The reasonable location of thermal power plant will influence its economic operation and social sustainable development. So the paper mainly researches on the locating of thermal power plant. Firstly the paper builds a primary comprehensive evaluation index system for the location of thermal power plant. Then, reduce attribute by rough sets to obtain the final evaluation index. Next, combining all the qualitative and quantitative information by expert groups' decision making, the paper gets an optimal result for thermal power plant location based on interval-valued fuzzy number. Finally, to verify the feasibility of the method, the paper takes some thermal power factory's locating as an example. The example proves that it is scientific and practical to use the interval-valued fuzzy number based on rough sets for location of power plant location. KEYWORD: Thermal power plant; Location; Interval-valued fuzzy number; Rough sets
\end{abstract}

\section{INTRODUCTION}

With the development of society, environmental awareness gradually enhances. Protecting the environment and saving resources gradually become the focus of attention. A reasonable location of power plant will make good benefits on society and environment, such as saving energy, improving environmental quality and people's life quality, improving the soft environment for investment promotion and capital introduction[1]. Otherwise, it will bring great adverse impacts such as heating costs increasing, resources and energy waste and environment pollution. Therefore, how to choose proper thermal power plant sites has vital practical significance.

Statistically, there are a few numbers of literatures about thermal power plant location problem[2-3]. This paper used rough sets to make attribute reduction for siting index, so that the index system is consistent with practical problems. The general location problems use analytic hierarchy process[4], which uses certain number to express and deal with subjective judgment. Therefore, the indicator system ignores the characteristic of fuzzy in thermal power plant location problem. However, the method of interval fuzzy number can effectively avoid the uncertainty which comes from the fuzzy characteristic, and it can better reflect the psychology of decision makers[5]. This journal will use interval fuzzy number evaluation method to research the thermal power plant location problem, based on using rough sets to build the location index system of thermal power plant.

\section{ROUGH SETS}

The core content of rough sets (RS) theory is the attribute reduction[6]. The related indicators of thermal power plant selection include economic indicators, technical indicators and social indicators. Its main characteristics are informative and indicator redundancy. Using rough sets method to make attribute reduction can help the evaluation model reduce the amount of data to be processed, so as to make the evaluation results more succinct.

The initial knowledge expression system of rough sets can be defined as

$$
S=\langle U, A, V, f\rangle
$$

Where $U$ is domain, $A=C_{1} \cup D$ and $C_{1}$ is condition attribute. $D$ is decision attribute. $A$, the collection of two constitute, is a nonblank finite attribution set. $V=\bigcup_{a \in A} V_{a}$ is the set of attribute value. $V_{a}$ is the range of the attribute of $a \in A$. Information function is $f: U \times A \rightarrow V, f\left(x_{i}, a\right) \in V . f$ assigns each attribute value in the domain.

The sustain degree from condition attribute $C_{l}$ to decision attribute $D$ defined as 


$$
k=\gamma_{c_{1}}(D)=\frac{P O S_{c_{1}}(D)}{|U|}
$$

Where $P O S_{C l}$ is named $C_{1}$ positive region of $D$, which means those sets that elements can be completely certain put into set $D$ from $U$ by knowledge. $\gamma_{c_{1}}(D)$ means ratio of the object that can be exactly put into decision class $U / D$ under attribute $C_{l}$. It describes the sustain degree from condition attribute to decision attribute. It can also be used to measure the classification ability of the system.

When measuring the significance of classification attribute subset $B^{\prime} \subseteq B$ coming from attribute set $D$, we can use difference between the two degree of dependency to weigh, that is

$$
\Delta k=r_{B}(D)-r_{B-B^{\prime}}(D)
$$

Where $\Delta k$ represents the degree of the affects of positive region of classification $U / D$ when classifying after getting rid of some attribute subset $B$ ' from set $B$. The larger the attribute is, the more important the value is.

Besides, there are some essential core attributes in a decision system.

\section{INTERVAL-VALUED FUZZY NUMBER}

There are $m$ evaluation objects $b_{1,} b_{2}, \mathrm{~L} b_{m}$ and $n$ indexes $d_{1}, d_{2}, \mathrm{~L} d_{n}$. A set of interval number correspond to indicators and evaluation objects. $a^{L}$ and $a^{R}$ is a set of precise number, they meet $\left[a^{L} \leq a^{R}\right]$, and build up matrix $A=\left(a_{i j}\right)_{m \times n}$.

$$
\text { 1) } \begin{aligned}
r_{i j}^{L} & =\frac{a_{i j}^{L}}{\sum_{i=1}^{m} a_{i j}^{R}}, r_{i j}^{R}=\frac{a_{i j}^{R}}{\sum_{i=1}^{m} a_{i j}^{L}} \\
r_{i j} & =\left(r_{i j}^{L}, r_{i j}^{R}\right)
\end{aligned}
$$

2) The index $S i j$ obeys normal distribution $N=\left(\mu_{I J}, \sigma_{i j}^{2}\right)$, so

$$
\begin{aligned}
& \mu_{i j}=\frac{1}{2}\left(r_{i j}^{L}+r_{i j}^{R}\right), \sigma_{i j}=\frac{1}{6}\left(r_{i j}^{R}-r_{i j}^{L}\right) \\
& Z_{i j}=\mu_{i j}+\varsigma\left(1-\sigma_{i j}\right), \quad \varsigma(0 \prec \varsigma \prec 1 / 2)
\end{aligned}
$$

3) Use coefficient of variation method to determine weights.

$$
d(a, b)=\|a-b\|=\sqrt{\left(a^{L}-b^{L}\right)^{2}+\left(a^{R}-b^{R}\right)^{2}}
$$

Finding $a_{j}^{*}=\left\lfloor a_{j}^{L}, a_{j}^{R}\right\rfloor$ from the matrix $A$.

For positive indicators:

$$
a_{j}^{L}=\max _{i} a_{i j}^{L}, a_{j}^{R}=\max _{i} a_{i j}^{R}
$$

Use the Equation 4 to get matrix $B=\left(b_{i j}\right)_{m \times n}$.

Compute the standard deviation for evaluation index $j$

$$
\begin{aligned}
& D_{j}=\sqrt{\frac{1}{m-1} \sum_{i=1}^{m}\left(b_{i j}-\overline{b_{j}}\right)^{2}} \\
& \left(b_{j} \text { is the medium for evaluation index } j\right)
\end{aligned}
$$

Calculate the variation coefficient for evaluation index $j$ :

$$
c_{j}=D_{j} / \bar{b}_{j} \text {. }
$$

After normalizing, we can get the index weight

$$
\omega_{j}=c_{j} / \sum_{j=1}^{n} c_{j}
$$

The weight vector is $W=\left(\omega_{1}, \omega_{2}, L, \omega_{n}\right) f 0$.

4) Utilize the weights and matrix $Z$ and get the final value.

$$
Z_{i}=\sum_{j=1}^{n} z_{i j} \omega_{j}
$$

\section{SETTING UP INDEX SYSTEM}

\subsection{Primary choice of index}

Economic indexes(A): investment $\left(\mathrm{a}_{1}\right)$, payable period $\left(a_{2}\right)$, operating $\operatorname{cost}\left(a_{3}\right)$, sale profit $\left(a_{4}\right)$, total project duration $\left(\mathrm{a}_{5}\right)$.

Technical indexes(B): landform $\left(\mathrm{b}_{1}\right)$, dust storage site conditions $\left(b_{2}\right)$, coal and water supply conditions $\left(b_{3}\right)$, traffic conditions $\left(b_{4}\right)$, line corridors conditions $\left(b_{5}\right)$, Grid access structure $\left(b_{6}\right)$, distance from the center of the heat $\operatorname{load}\left(b_{7}\right)$, roadway and network paving $\operatorname{cost}\left(\mathrm{b}_{8}\right)$, availability of land $\left(\mathrm{b}_{9}\right)$, quantity of earthwork $\left(b_{10}\right)$, pipeline condition $\left(b_{11}\right)$, geological condition $\left(\mathrm{b}_{12}\right)$.

Social indexes $(C)$ : employment benefits $\left(c_{1}\right)$, the local government and public's opinion $\left(\mathrm{c}_{2}\right)$, workers' living conditions $\left(\mathrm{c}_{3}\right)$, potential of promoting the development of national economy $\left(c_{4}\right)$, environmental impact assessment of water resources $\left(\mathrm{c}_{5}\right)$, atmospheric environment impact evaluation $\left(\mathrm{c}_{6}\right)$, environmental impact assessment for soil $\left(\mathrm{c}_{7}\right)$, environmental impact assessment for noise $\left(\mathrm{c}_{8}\right)$, environmental impact assessment for waste $\left(\mathrm{c}_{9}\right)$. 


\subsection{Reduction of rough set indicators}

This paper collected data which was marked by 15 energy experts.

Discretize the data by Equal Frequency. Reducing attribute by using Johnson's Algorithm, we can get the reduction set $\left[a_{1}, b_{1}, b_{2}, b_{4}, b_{10}, b_{11}, b_{12}\right\rfloor$.

\subsection{The evaluation indexes}

According to site construction condition and the characteristics of interval fuzzy number, the paper builds the site selection index system shown in Table1. The purpose of the index system is to balance social, economic and ecological benefits.

Table 1.The indexes after reduction

\begin{tabular}{|l|l|}
\hline & Index \\
\hline $\mathrm{S}_{1}$ & Investment \\
\hline $\mathrm{S}_{2}$ & Landform \\
\hline $\mathrm{S}_{3}$ & Dust storage site condition \\
\hline $\mathrm{S}_{4}$ & Traffic condition \\
\hline $\mathrm{S}_{5}$ & Quantity of earthwork \\
\hline $\mathrm{S}_{6}$ & Pipeline condition \\
\hline $\mathrm{S}_{7}$ & Geological condition \\
\hline
\end{tabular}

\section{EMPIRICAL ANALYSIS}

There are two choices of factory locations A and B, the two sites are about $1 \mathrm{~km}$ apart. Site A is about $6.50 \mathrm{~km}$ apart from city center, and Site B is about $5.50 \mathrm{~km}$

In the following, the paper will evaluate and optimize the sites, including two alternative A and B and the original site. The author plans to use interval-valued fuzzy number as the basis of research. Provide decision basis for decision makers to choose the appropriate factory. The general idea is as following. Firstly, chooses score result from 15 experts' interval mark for the original address $\left(X_{1}\right)$, site $\mathrm{A}\left(X_{2}\right)$, site $\mathrm{B}\left(X_{3}\right)$, that its scores' interval belongs to $[0,1]$. Finally, take back 13 effective questionnaires and 2 copies of invalid questionnaire.

Then compare each factor and conclude the weight of each factor value. Through the calculating of weight the author finds out the scientific and reasonable land plan for projects. Cope with the 13 effective score and comes out Table 2.
Table 2.Score index within the interval (matrix A)

\begin{tabular}{|l|c|c|c|}
\hline & $\mathrm{X}_{1}$ & $\mathrm{X}_{2}$ & $\mathrm{X}_{3}$ \\
\hline $\mathrm{S}_{1}$ & {$[0.73,0.76]$} & {$[0.79,0.82]$} & {$[0.80,0.81]$} \\
\hline $\mathrm{S}_{2}$ & {$[0.76,0.79]$} & {$[0.81,0.84]$} & {$[0.80,0.82]$} \\
\hline $\mathrm{S}_{3}$ & {$[0.72,0.75]$} & {$[0.69,0.71]$} & {$[0.68,0.70]$} \\
\hline $\mathrm{S}_{4}$ & {$[0.88,0.91]$} & {$[0.85,0.88]$} & {$[0.84,0.86]$} \\
\hline $\mathrm{S}_{5}$ & {$[0.71,0.74]$} & {$[0.86,0.89]$} & {$[0.85,0.87]$} \\
\hline $\mathrm{S}_{6}$ & {$[0.73,0.77]$} & {$[0.89,0.92]$} & {$[0.86,0.89]$} \\
\hline $\mathrm{S}_{7}$ & {$[0.70,0.72]$} & {$[0.74,0.76]$} & {$[0.77,0.80]$} \\
\hline
\end{tabular}

(1) Get the matrix $\mathrm{R}$ as Table 3 .

Table 3. Matrix R

\begin{tabular}{|c|c|c|}
\hline$[0.305,0.328]$ & {$[0.331,0.353]$} & {$[0.335,0.349]$} \\
\hline$[0.310,0.333]$ & {$[0.331,0.354]$} & {$[0.327,0.346]$} \\
\hline$[0.333,0.359]$ & {$[0.319,0.340]$} & {$[0.315,0.335]$} \\
\hline$[0.332,0.354]$ & {$[0.321,0.342]$} & {$[0.317,0.335]$} \\
\hline$[0.284,0.306]$ & {$[0.344,0.368]$} & {$[0.340,0.360]$} \\
\hline$[0.283,0.310]$ & {$[0.345,0.371]$} & {$[0.333,0.359]$} \\
\hline$[0.307,0.326]$ & {$[0.325,0.344]$} & {$[0.338,0.362]$} \\
\hline
\end{tabular}

(2)Choose $\varsigma=1 / 3$, get the matrix $\mathrm{Z}$ by Equation 5:

$Z=\left[\begin{array}{lllllll}0.649 & 0.654 & 0.678 & 0.675 & 0.627 & 0.629 & 0.649 \\ 0.674 & 0.675 & 0.662 & 0.664 & 0.688 & 0.690 & 0.666 \\ 0.674 & 0.669 & 0.657 & 0.658 & 0.682 & 0.678 & 0.682\end{array}\right]$

(3) Find out $a_{j}^{*}=\left[a_{j}^{L}, a_{j}^{R}\right]$ by Equation 7 .

$$
\begin{array}{ll}
a_{1}^{*}=[0.800,0.820] & a_{2}^{*}=[0.810,0.840] \\
a_{3}^{*}=[0.720,0.750] & a_{4}^{*}=[0.880,0.910] \\
a_{5}^{*}=[0.860,0.890] & a_{6}^{*}=[0.890,0.920]
\end{array}
$$

$a_{7}^{*}=[0.770,0.800]$

(4) Arrive at the weights by the variation coefficient method. Make matrix A from matrix B:

$\mathrm{B}=\left[\begin{array}{ccccccc}0.092 & 0.071 & 0 & 0 & 0.212 & 0.219 & 0.106 \\ 0.01 & 0 & 0.05 & 0.042 & 0 & 0 & 0.05 \\ 0.01 & 0.022 & 0.064 & 0.064 & 0.022 & 0.042 & 0\end{array}\right]$

(5) Calculate the average of seven columns, respectively.

$\bar{b}_{1}=0.037 \quad \bar{b}_{2}=0.031 \quad \bar{b}_{3}=0.038 \quad \bar{b}_{4}=0.035$

$\bar{b}_{5}=0.078 \quad \bar{b}_{6}=0.087 \quad \bar{b}_{7}=0.052$

(6) Calculate deviation:
$D_{1}=0.0473$
$D_{2}=0.0363$
$D_{3}=0.0336$
$D_{4}=0.0325$
$D_{5}=0.1166$
$D_{6}=0.1162$
$D_{7}=0.053$ 
(7) Then calculate the coefficient of variation:

$$
\begin{array}{llll}
c_{1}=1.2784 & c_{2}=1.171 & c_{3}=0.8842 & c_{4}=0.9286 \\
c_{5}=1.4949 & c_{6}=1.3356 & c_{7}=1.0192
\end{array}
$$

(8) Carry out normalization processing, obtain weight vector:

$$
w=[0.1576,0.1444,0.109,0.1145,0.1843,0.1646,0.1256]
$$

(9) The value of the final evaluation:

$$
Z_{1}=0.648 \quad{ }_{2} Z 0.67 \quad Z_{3}=0.673
$$

(10) Then we can confirm the order:

$$
Z_{2}>Z_{3}>Z_{1}
$$

\section{CONCLUSION}

According to the above analysis, the paper makes final conclusions.

1) The best scheme is the site of A, the site $B$ comes second.

2) In the analytical process, the alternative site of $\mathrm{A}$ is about $6.5 \mathrm{~km}$ apart from the city center, located in the northwest of the city. Its dominant wind direction for the whole year is SSE and S. It brings less influence on the city than site of B does, and is more beneficial than the old one. In the tendency of building up an economic system while ensures ecologically friendly and sustainable development, to choose the site of $\mathrm{A}$ is more beneficial for environment protecting and economy development than B site does.

3) Although the site of A is the best scheme, it is further from city center than the site of $B$, so the distance of heating supply is more further. This is the deficiency of the A scheme. It needs to be improved.

The location of thermal power plant is closely related to the energy-saving, emission-reduction and the stable economy operation of the power plant. The interval fuzzy is applied to site selection in this paper. It combines quantitative and qualitative methods to make scientific decisions and has some reference value for making scientific decisions and improving comprehensiveness, scientificity and veracity of the location of power plant construction project. Interval fuzzy number bases on a systematic math theory, its calculation process is more rigorous. By using this method, the economical, social and ecological benefits are balanced to maximize the comprehensive benefit. In the process of using interval fuzzy, some evaluation indexes are simplified, only several aspects such as siting and traffic conditions are researched in order to state the feasibility of the method in the siting. However, this evaluation method cannot provide new schemes for decision-making, which is a defect of this method. It's hoped that the defect will be improved in the later research.

\section{REFERENCES}

[1] Ramos D S,Lima W S. Site selection and economic risks for ther-mal power plant projects under the new Brazilian regulatory framework. Proceedings of International Conference on Power System Technology. 2000

[2] Yunna Wu, Shuai Geng, Haobo Zhang, Min Gao. Decision framework of solar thermal power plant site selection based on linguistic Choquet operator. Applied Energy, 2014, Vol.136

[3] Jia Li, Tim Cockerill, Xi Liang, Jon Gibbins. Locating new coal-fired power plants with Carbon Capture Ready design-A GIS case study of Guangdong province in China. Energy Procedia, 2011, Vol.4, pp.2824-2830

[4] Zhang Yong, Zhang Zhi-guo, Li Jin-feng, Xue Li-ping, Du Yi. Analytic hierarchy process in the power plant construction projects land of the application of the location. Modern agriculture science and technology, 2009, the second issue.

[5] Hung-Lin Lai, Ting-Yu Chen. A fuzzy risk-assessment method using a TOPSIS approach based on intervalvalued fuzzy numbers. Journal of the Chinese Institute of Industrial Engineers, 2011, Vol.28 (6), pp.467-484

[6] Pawalk Z. Rough Sets. Theoretical Aspects of Reasoning about Data. 1991 